\title{
Pharmacodynamic and pharmacokinetic study of pegylated liposomal doxorubicin combination (CCOP) chemotherapy in patients with peripheral T-cell lymphomas
}

\author{
Yun FAN ${ }^{1}$, Neng-ming LIN $^{2, *}$, Lü-hong LUO ${ }^{1}$, Luo FANG ${ }^{2}$, Zhi-yu HUANG ${ }^{1}$, Hai-feng YU ${ }^{1}$, Feng-qin WU ${ }^{1}$ \\ ${ }^{1}$ Department of Chemotherapy Center, Zhejiang Cancer Hospital, Hangzhou 310022, China; ${ }^{2}$ Laboratory of Clinical Pharmacy, Zhejiang \\ Cancer Hospital, Hangzhou 310022, China
}

\begin{abstract}
Aim: To investigate the pharmacodynamic and pharmacokinetic parameters of pegylated liposomal doxorubicin (PLD) combined with cyclophosphamide, vincristine, and prednisolone in patients with peripheral T-cell lymphomas (PTCL).

Methods: Seven chemonaive patients and four patients with relapsed peripheral T-cell lymphomas were treated with a CCOP regimen consisting of an intravenous administration of cyclophosphamide $\left(750 \mathrm{mg} / \mathrm{m}^{2}\right)$, vincristine $\left(1.4 \mathrm{mg} / \mathrm{m}^{2}\right)$, and PLD $\left(30 \mathrm{mg} / \mathrm{m}^{2}\right)$ on d 1 , as well as an oral administration of prednisolone $\left(60 \mathrm{mg} / \mathrm{m}^{2}\right)$ on $\mathrm{d} 1-5$. This regimen was repeated every 3 weeks for six cycles, and the clinical response and toxicity of the regimen were monitored. In addition, the plasma concentration of PLD at different time points was determined before and after treatment. The pharmacokinetics (PKs) software was used to estimate the pharmacokinetic parameters of PLD.

Results: The 11 PTCL patients received 35 treatment cycles. Three of them achieved complete response (CR), two partial response $(\mathrm{PR})$, four stable disease (SD), and two progressive disease (PD). The overall response rate (ORR) was $45.5 \%$, and the CR rate was 27.3\%. In the 7 chemonaive patients, three achieved CR, two PR, one SD, and one PD. The ORR was $71.4 \%$, and CR rate was $42.9 \%$. The median follow-up time was 15 months, but 6 out of 11 patients were dead at the time of data analysis. The 1-year overall survival rate was 45.5\%, and the median progression-free survival (PFS) rate was 6.5 [95\% confidence interval $(95 \% \mathrm{Cl}) 3.17-19.02$ ] with a survival rate of 11.5 months $(95 \% \mathrm{Cl} 6.65-16.36)$. The main toxicity was myelosuppression. Oral mucositis and hand-foot syndrome seldom occurred. The PLD plasma concentration from nine patients ranged from 1.7036 to $9.2207 \mathrm{mg}^{-1}$ after administration of the CCOP regimen $(0-168 \mathrm{~h})$. The pharmacokinetic parameters $\mathrm{AUC}_{0-\infty}, \mathrm{CL}, t_{1 / 2}$, and $V_{\mathrm{d}}$ were $910.76 \mathrm{mg} / \mathrm{L} \cdot \mathrm{h}, 0.043 \mathrm{~L} \cdot \mathrm{h}^{-1} \cdot \mathrm{m}^{-2}, 68.40 \mathrm{~h}$, and $3.56 \mathrm{~L} / \mathrm{m}^{2}$, respectively.

Conclusion: The CCOP regimen was effective and well tolerated in patients with peripheral T-cell lymphomas. The results of the pharmacokinetic parameters showed that PLD had long retention time in blood circulation.
\end{abstract}

Keywords: pegylated liposomal doxorubicin; peripheral T-cell lymphomas; pharmacodynamics; pharmacokinetics; cyclophosphamide; vincristine; prednisolone

Acta Pharmacologica Sinica (2011) 32: 408-414; doi: 10.1038/aps.2010.217

\section{Introduction}

Peripheral T-cell lymphomas (PTCL) are a group of rare and heterogeneous non-Hodgkin lymphoma (NHL), which have a poor prognosis and low survival rate ${ }^{[1]}$. The 5 -year overall survival (OS) for common subtypes of PTCL, such as PTCL not otherwise specified (NOS) and angioimmunoblastic T-cell lymphoma, is $32 \%$ compared with only $14 \%$ for adult T-cell

\footnotetext{
* To whom correspondence should be addressed. E-mail Inm1013@163.com

Received 2010-08-08 Accepted 2010-12-02
}

leukemia lymphoma ${ }^{[2]}$, and there is no standard treatment regimen at present. High-dose therapy and autologous stemcell transplants are still controversial ${ }^{[3,4]}$. The regimen of cyclophosphamide, doxorubicin, vincristine, and prednisolone (CHOP) remains the most commonly used chemotherapeutic treatment for PTCL. However, CHOP has poor efficacy, a low CR rate $(10 \%-60 \%)$ and a median overall survival (OS) of $<3$ years $^{[5-7]}$. Moreover, doxorubicin has a low therapeutic index and significant treatment-related toxicities, whereas pegylated liposomal doxorubicin (PLD) has a stable spatial structure and demonstrates reduced binding to plasma proteins. Com- 
pared to conventional doxorubicin injection, PLD has a longer retention time in blood circulation, lower cardiotoxicity and improved targeted efficiency ${ }^{[8]}$. Recently, there have been several clinical studies on PLD-based NHL treatment that have shown it to be superior in the treatment of the elderly or patients with primarily cutaneous T-cell lymphomas (CTCL) with aggressive $\mathrm{NHL}^{[9-11]}$.

However, there are few relative studies on the pharmacodynamic and pharmacokinetic characteristics of the cyclophosphamide, vincristine, PLD, and prednisolone (CCOP) regimen in PTCL patients. In this study, we aimed to investigate the efficiency and toxicities of a PLD-based CCOP regimen in PTCL patients, and to study the pharmacokinetics of PLD by determining its plasma concentrations at different time points after administration.

\section{Materials and methods} Patient eligibility criteria

Patients were eligible for this study if they had histologically confirmed chemonaive or relapsed PTCL (except external precursor T-cell lymphomas) with at least one measurable lesion. The patients met several other eligibility criteria: (1) no current chemotherapy or radiotherapy treatment; (2) Eastern Cooperative Oncology Group (ECOG) performance status (PS) of $0-2$; (3) age between 18 and 75 years; (4) survival prediction $\geq 3$ months; (5) acceptable hematologic parameters [white blood cell $(\mathrm{WBC}) \geq 3.5 \times 10^{9} \mathrm{~L}^{-1}$, absolute neutrophil count (ANC) $\geq 1.5 \times 10^{9} \mathrm{~L}^{-1}$, hemoglobin $(\mathrm{HB}) \geq 9.0 \mathrm{~g} / \mathrm{L}$, and platelets $\geq 100 \times 10^{9}$ $\left.\mathrm{L}^{-1}\right]$; and (6) adequate hepatic and renal functions (liver: bilirubin $\leq 1.5$ times the upper limit of normal (ULN), aspartate aminotransferase/alanine amiotransferase (AST/ALT) $\leq 1.5$ times ULN or $\leq 5$ times ULN if hepatic metastases were present; kidney: serum creatinine $\leq 1.5$ times ULN or creatinine clearance $\geq 50 \mathrm{~mL} / \mathrm{min}$ ). The following groups were excluded: (1) pregnant or lactating women; (2) patients with other malignant tumors, except for carcinoma of the cervix uteri in situ and basal cell carcinoma of the skin; (3) patients with reactivated infection; and (4) patients with serious or untreated cardiac disease. The study was approved by the Ethics Committee of Zhejiang Cancer Hospital and all patients gave written informed consent.

\section{Treatment plan}

Patients received an intravenous (iv) infusion of cyclophosphamide $\left(750 \mathrm{mg} / \mathrm{m}^{2}\right)$ within $10 \mathrm{~min}$, vincristine $(1.4 \mathrm{mg} /$ $\mathrm{m}^{2}$ ) within $15 \mathrm{~min}$, and pegylated liposomal doxorubicin (30 $\left.\mathrm{mg} / \mathrm{m}^{2}\right)$ within one hour on $\mathrm{d} 1$. Prednisolone $(100 \mathrm{mg})$ was administered orally on $\mathrm{d} 1$ to $\mathrm{d} 5$, and the entire regimen was repeated every 3 weeks for six cycles. Before the treatment a $5-\mathrm{HT}_{3}$ receptor antagonist was used to prevent vomiting. Granulocyte colony-stimulating factor (G-CSF) was not used in the first course as regular prevention, but it was used in the next course if grade 3/4 granulocytopenia and febrile neutropenia were present. Treatment was delayed if grade 3/4 hematologic toxicities, grade $2 / 4$ mucositis or skin toxicities occurred.

\section{Response analysis}

Response to therapy was assessed every two cycles according to the Response Evaluation Criteria in Solid Tumors (RECIST), which included complete responses (CR), partial responses $(\mathrm{PR})$, stable disease (SD), progressive disease (PD), and CR plus $\mathrm{PR}$ as overall response rate (ORR). Patients who were evaluated as CR, PR, and SD continued treatment. Patients who were evaluated as CR and PR were reexamined after 4 weeks. The Kaplan-Meier Survival Analysis was performed by SPSS software (version 16.0).

\section{Toxicity analysis}

Toxicity was evaluated every cycle according to the National Cancer Institute Common Toxicity Criteria, version 3.0.

\section{Pharmacokinetics study \\ Reagents and materials}

Pegylated liposomal doxorubicin $\left(\right.$ Caelyx $\left.^{\circledR}\right)$ was provided by Ben Venue Laboratories Inc (Bedford, USA). Doxorubicin reference $(98.8 \%$ ) was provided by Zhejiang Hisun Pharmaceutical Co Ltd (Taizhou, China). The internal standard daunorubicin reference $(98.0 \%)$ was obtained from Zhejiang Hisun Pharmaceutical Co Ltd (Taizhou, China). All other chemicals and solvents were of chromatographic or analytical grade and were obtained from several commercial sources. Drugfree heparinized human plasma was obtained from Hangzhou Central Blood Station (Hangzhou, China).

\section{Chromatographic equipment and conditions}

The Agilent 1100 high-performance liquid chromatography (HPLC) system was equipped with a G1311A pump, a G1314A programmable diode array detector (DAD) and a G1313A auto-injector. A Hewlett Packard (HP) 1000 computer with in-house developed software was used for on-line data acquisition and subsequent calculations. Separation was carried out using a Zorbax Elipse XDB-C18 (5 $\mu \mathrm{m}, 4.6 \mathrm{~mm} \times 150 \mathrm{~mm}$, Agilent) column at $25{ }^{\circ} \mathrm{C}$ and detected at $254 \mathrm{~nm}$. The mobile phase consisted of acetonitrile and $40 \mathrm{mmol} / \mathrm{L}$ ammonium acetate buffer solution. Samples were eluted in gradient mode (Table 1), and the flow rate was $0.8 \mathrm{~mL} / \mathrm{min}$. The injection volume was $50 \mu \mathrm{L}$. This method resulted in good separations (Figure 1).

\section{Preparation of stock and standard solutions}

A reference stock solution of doxorubicin (940.0 mg/L) and an

Table 1. The linear gradient elution of the mobile phase.

\begin{tabular}{ccc}
\hline Time $(\min )$ & Acetonitrile $(\%)$ & Buffer $(\%)$ \\
\hline 0 & 10 & 90 \\
5 & 10 & 90 \\
10 & 15 & 85 \\
15 & 20 & 80 \\
25 & 40 & 60 \\
30 & 40 & 60 \\
\hline
\end{tabular}



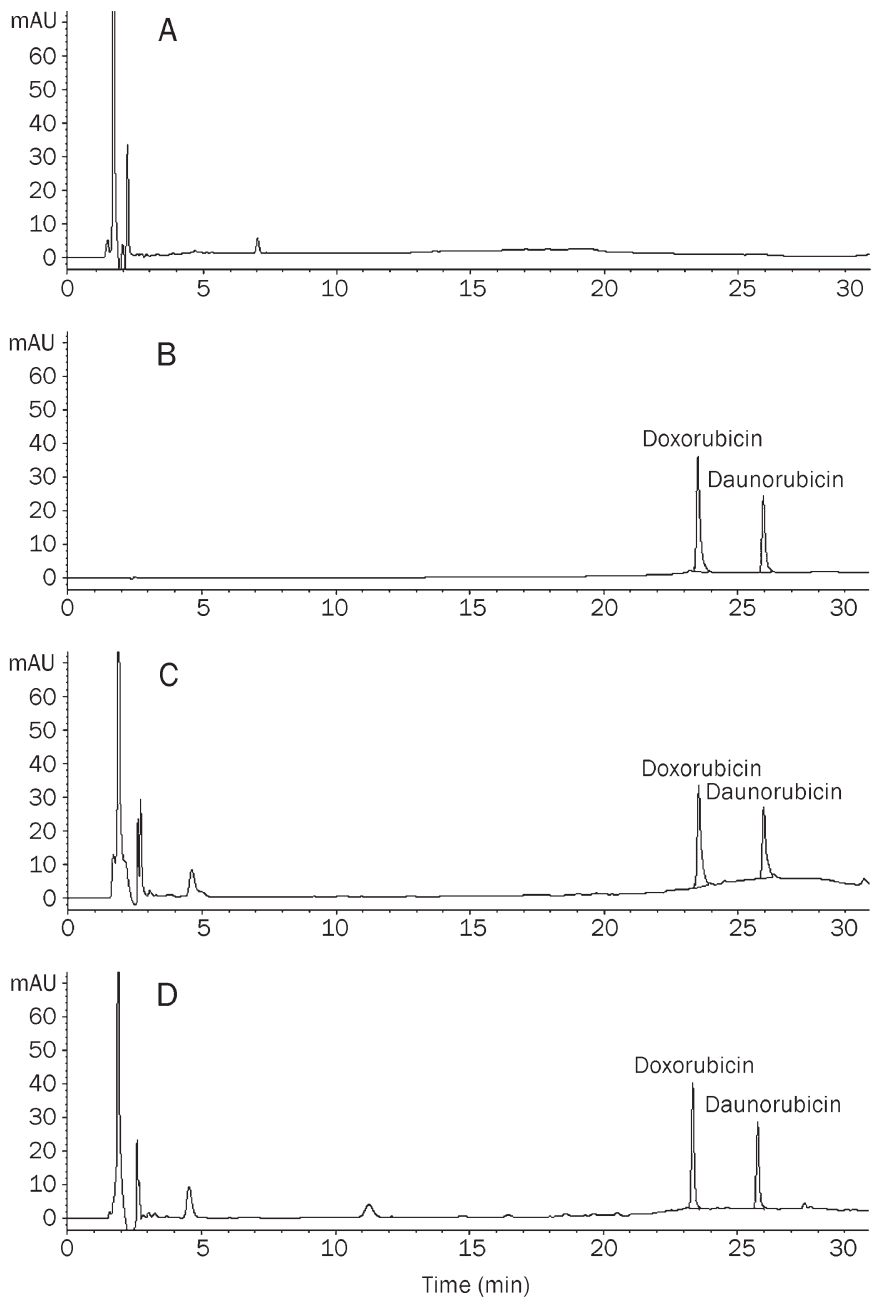

Figure 1. HPLC chromatograms.

internal standard solution of daunorubicin $(20.4 \mathrm{mg} / \mathrm{L})$ were prepared in sterile water $\left(\mathrm{pH}\right.$ 6.8) and stored at $4{ }^{\circ} \mathrm{C}$ until use.

\section{Assay procedure}

The internal standard solution $(100 \mu \mathrm{L})$ was added to drugfree human plasma $(0.5 \mathrm{~mL})$ and vortexed for one minute, followed by the addition of a $20 \%$ zinc sulfate methanol solution $(0.6 \mathrm{~mL})$. The sample was vortexed for one minute and then centrifuged at 10000 round per minute for $10 \mathrm{~min}$. The supernatant was filtered using a $0.45 \mu \mathrm{m}$ filter and then $50 \mu \mathrm{L}$ was injected into the liquid chromatography (LC) system.

\section{Calibration curve preparation}

A series of drug-free human plasma was mixed with different concentrations of doxorubicin; the final concentrations of doxorubicin were $0.18,0.36,0.73,1.46,2.93,5.87,11.75,23.50$, 47.00, and $94.00 \mathrm{mg} / \mathrm{L}$. Five replicates were prepared for each concentration of doxorubicin. The calibration curves were obtained by plotting the peak area ratio $(y)$ of doxorubicin over internal standard versus doxorubicin concentration. The regression equations of doxorubicin at low concentra- tions (0.18-2.93 $\mathrm{mg} / \mathrm{L})$ and high concentrations (2.93-94.00 $\mathrm{mg} / \mathrm{L}$ ) were $y=0.2378 x-0.0161, r=0.9997$, and $y=0.262 x-0.3315$, $r=0.9992$, respectively. The limit of detection (LOD) and the limit of quantification (LOQ) were $0.06 \mathrm{mg} / \mathrm{L}$ and $0.1 \mathrm{mg} / \mathrm{L}$, respectively, for doxorubicin. The average recoveries of doxorubicin at various concentrations were $97.8 \%-110.2 \%$. For intra- and inter-day precision, the corresponding standard deviations of the measurements were both less than $5.74 \%$.

\section{Pharmacokinetic studies and analysis}

Blood samples were collected during the first cycle. Approximately $3 \mathrm{~mL}$ of whole blood samples were collected from patients' forearm veins into heparinized polypropylene centrifuge tubes before pegylated liposomal doxorubicin was infused as well as at $0.75,2,8,24,48,72,120$, and $168 \mathrm{~h}$ after infusion. The blood samples were immediately placed on ice. Plasma was obtained by centrifugation of the samples (3000 round per minute for $10 \mathrm{~min}$ at $4^{\circ} \mathrm{C}$ ) and then stored at $-20^{\circ} \mathrm{C}$ until analysis. The plasma concentration-time data were analyzed by pharmacokinetic software for fitting the pharmacokinetic model and estimating the pharmacokinetic parameters.

\section{Statistical analysis}

Pharmacodynamic data were calculated using SPSS software (version 16.0). Pharmacokinetic parameters were obtained by DAS software (Drug and Statistics version 2.1.1, Mathematical Pharmacology Professional Committee of China, Shanghai, China). Data were expressed as the mean \pm SD. The mean values with $95 \%$ confidence interval and $t$-test were used to determine statistical significances in comparing pharmacokinetics between male and female patients (SPSS software, version 16.0$) . \quad P<0.05$ was considered statistically significant.

\section{Results}

Patient characteristics

Eleven patients with PTCL were enrolled in this study from February 2006 to December 2008. There were seven male and four female patients, and their median age was 36 years (range: 28-65 years). Seven patients were chemonaive, and four had relapsed (Table 2). Eight patients had performance status (PS) 0-1 and three had PS 2; four patients were in stage I-II, seven patients were in stage III-IV, and six patients had B symptoms. The serum lactate dehydrogenase (LDH) of seven patients was elevated. Patients were evaluated using the International Prognostic Index (IPI) score: six patients were given a score of $0-1$, three were given a score of 2 and two were given a score of 3 . The pathological types were PTCL and NOS (six cases), nasal type of NK/T-cell lymphoma (two relapsed cases after radiotherapy), angioimmunoblastic T-cell lymphoma (one case), anaplastic large cell lymphoma (one case of ALK negative), and $\gamma-\delta$ cell skin lymphoma (one case).

\section{Treatment received}

A total of 35 cycles of chemotherapy was administered, with a median number of 3.2 cycles (range: $2-6$ cycles). Six patients received 2 treatment cycles, one patient received 3 cycles, two 
Table 2. Clinical characteristics of 11 patients with PTCL.

\begin{tabular}{|c|c|}
\hline Parameters & Score \\
\hline Median age (year) & 36 \\
\hline Age range (year) & $28-65$ \\
\hline Male $(\%)$ & $63.6(n=7)$ \\
\hline Female $(\%)$ & $36.4(n=4)$ \\
\hline Body surface area $\left(\mathrm{m}^{2}\right)$ & 1.67 \\
\hline Body weight (kg) & 64.3 \\
\hline \multicolumn{2}{|l|}{ Performance status (ECOG) } \\
\hline $0-1(\%)$ & $72.7(n=8)$ \\
\hline $2(\%)$ & $27.3(n=3)$ \\
\hline \multicolumn{2}{|l|}{ Stage } \\
\hline I-II (\%) & $36.4(n=4)$ \\
\hline III-IV (\%) & $63.6(n=7)$ \\
\hline B symptoms $(\%)$ & $54.5(n=6)$ \\
\hline Elevated serum LDH (\%) & $63.6(n=7)$ \\
\hline \multicolumn{2}{|l|}{ IPI scores } \\
\hline $0-1(\%)$ & $54.5(n=6)$ \\
\hline $2(\%)$ & $27.3(n=3)$ \\
\hline $3(\%)$ & $18.2(n=2)$ \\
\hline \multicolumn{2}{|l|}{ Pathological types } \\
\hline PTCL, NOS (\%) & $54.5(n=6)$ \\
\hline Nasal type of NK/T-cell lymphoma (\%) & $18.2(n=2)$ \\
\hline Angioimmunoblastic T-cell lymphoma (\%) & $9.1(n=1)$ \\
\hline Anaplastic large cell lymphoma (ALK negative) (\%) & $9.1(n=1)$ \\
\hline$\curlyvee-\delta$ cell skin lymphoma $(\%)$ & $9.1(n=1)$ \\
\hline
\end{tabular}

patients received 4 cycles, and the remaining two patients received 6 cycles. Among the seven patients who received 2 or 3 treatment cycles, one quit the program due to poor compliance. The other six SD or PD patients received second-line chemotherapy. The remaining patients reached CR or PR, and two received high-dose therapy and autologous stem-cell therapy. Two patients received delayed treatment in 3 cycles. One NK/T cell lymphoma patient with B symptoms switched to the second-line regimen, received radiotherapy treatment and was still disease-free after the three months follow-up.

\section{Efficacy and survival}

Efficacy and survival were evaluated. Three patients had CR, two had PR, four had SD, and two had PD. The ORR was $45.5 \%$ and the CR rate was $27.3 \%$. For the seven chemonaive patients, three had CR, two had PR, one had SD, and one had PD; the ORR was $71.4 \%$ and the CR rate was $42.9 \%$. For the four relapsed patients, there was no CR or PR patient, but three patients had SD and one patient had PD. The median follow-up time for the 11 patients was 15 months (ranging from 5 to 36 months); however, six were dead as of the time of data analysis. The one-year overall survival rate was $45.5 \%$, and the median PFS (progression-free survival) and survival time were 6.5 months (95\% CI 3.17-19.02) and 11.5 months (95\% CI 6.65-16.36), respectively. A Kaplan-Meier curve for survival time was generated (Figure 2).

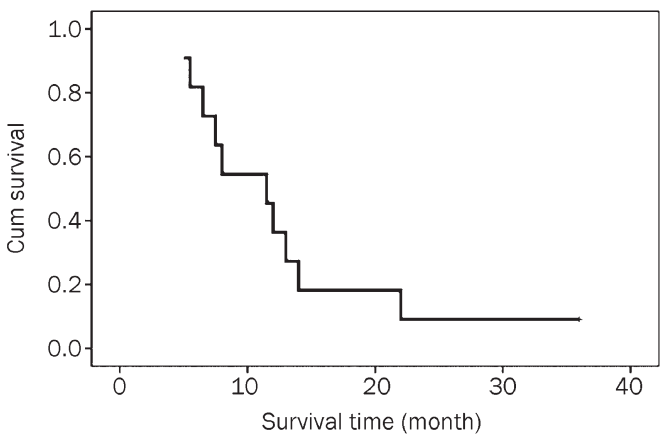

Figure 2. Survival curve for 11 patients with peripheral T-cell lymphomas treated with the CCOP regimen.

\section{Toxicity analysis}

The toxicity results of the 11 patients are shown in Table 3. Generally, the toxicities were tolerable. The main toxicities were myelosuppression including anemia (grade $3 / 4$, one case), neutropenia (grade 3/4, three cases) and thrombocytopenia (grade $3 / 4$, one case). The other toxicities were rare, with no treatment-related deaths.

Table 3. Toxicities of 11 patients with PTCL.

\begin{tabular}{lll}
\hline \multicolumn{1}{c}{ Toxicities } & Grade 1/2(\%) & Grade 3/4 (\%) \\
\hline Anaemia & $5(45.5)$ & $1(9.1)$ \\
Neutropenia & $4(36.4)$ & $3(27.3)$ \\
Febrile neutropenia & $2(18.2)$ & 0 \\
Thrombocytopenia & $3(27.3)$ & $1(9.1)$ \\
Nausea/Vomiting & $4(36.4)$ & 0 \\
SGOT/SGPT & $2(18.2)$ & 0 \\
Oral mucositis & $2(18.2)$ & 0 \\
Hand-foot syndrome & $1(9.1)$ & 0 \\
Alopecia & $2(18.2)$ & 0 \\
Cardiac toxicity & 0 & 0
\end{tabular}

SGOT, serum glutamic-oxaloacetic transaminase; SGPT, serum glutamicpyruvic transaminase.

\section{Plasma concentration analysis}

Blood samples from nine patients treated with a CCOP regimen (without dose modification) were analyzed for plasma concentrations. Initially, at $0-8 \mathrm{~h}$, plasma concentrations increased and peaked (8.490-9.221 $\mathrm{mg} / \mathrm{L})$, then they slowly decreased to an average level of $1.704 \mathrm{mg} / \mathrm{L}$ at $168 \mathrm{~h}$ (Figure 3).

\section{Pharmacokinetic analysis}

The plasma concentration-time data were processed by DAS software. Pegylated liposomal doxorubicin fits a biphasic kinetic model, and its pharmacokinetic parameters are shown in Table 4. The pharmacokinetic characteristics of pegylated liposomal doxorubicin injection were significantly different 


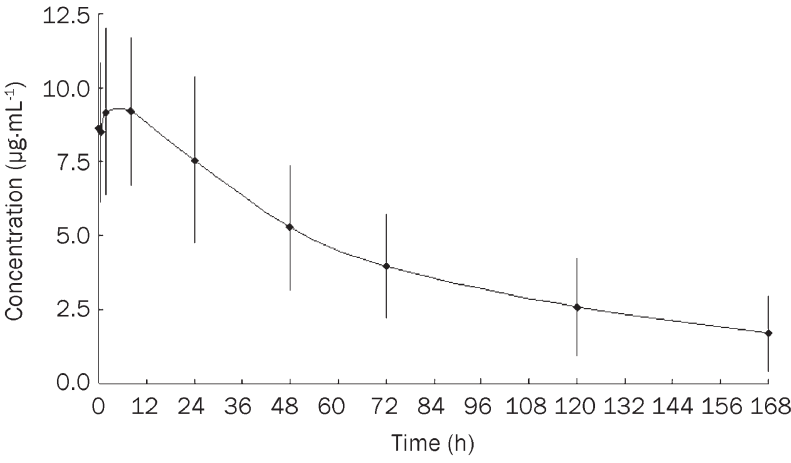

Figure 3. Plot of plasma concentration (mean \pm SD) versus time of doxorubicin in patients with PTCL treated with $30 \mathrm{mg} / \mathrm{m}^{2}$ of pegylated liposomal doxorubicin in combination with a CCOP regimen $(n=9)$.

Table 4. Pharmacokinetic parameters in patients with PTCL treated with $30 \mathrm{mg} / \mathrm{m}^{2}$ of pegylated liposomal doxorubicin in combination with CCOP regimen $(n=9)$.

\begin{tabular}{|c|c|c|c|c|c|}
\hline \multirow[b]{2}{*}{ Parameters } & \multirow[b]{2}{*}{ Mean } & \multirow[b]{2}{*}{ SD } & \multirow[b]{2}{*}{ SEM } & \multicolumn{2}{|c|}{$95 \% \mathrm{Cl}$} \\
\hline & & & & $\begin{array}{l}\text { Lower } \\
\text { bound }\end{array}$ & $\begin{array}{l}\text { Upper } \\
\text { bound }\end{array}$ \\
\hline $\mathrm{AUC}_{(0-\infty)}(\mathrm{mg} / \mathrm{L} \cdot \mathrm{h})$ & 910.76 & 462.33 & 154.12 & 555.38 & 1266.14 \\
\hline $\mathrm{AUC}_{(0-\mathrm{t})}(\mathrm{mg} / \mathrm{L} \cdot \mathrm{h})$ & 715.61 & 298.39 & 99.46 & 486.25 & 944.97 \\
\hline $\mathrm{CL}\left(\mathrm{L} \cdot \mathrm{h}^{-1} \cdot \mathrm{m}^{-2}\right)$ & 0.043 & 0.025 & 0.0083 & 0.0239 & 0.062 \\
\hline$C_{\max }(\mathrm{mg} / \mathrm{L})$ & 9.93 & 2.97 & 0.99 & 7.64 & 12.21 \\
\hline$t_{1 / 2}(\mathrm{~h})$ & 68.40 & 28.39 & 9.46 & 46.58 & 90.23 \\
\hline$t_{\max }(\mathrm{h})$ & 6.78 & 7.71 & 2.57 & 0.85 & 12.70 \\
\hline$V_{d}\left(L / m^{2}\right)$ & 3.56 & 1.13 & 0.38 & 2.69 & 4.42 \\
\hline
\end{tabular}

AUC, area under the curve; $\mathrm{CL}\left(\mathrm{L} \cdot \mathrm{h}^{-1} \cdot \mathrm{m}^{-2}\right)$, clearance; $C_{\max }(\mathrm{mg} / \mathrm{L})$, maximum concentration; $t_{1 / 2}(\mathrm{~h})$, half life time; $t_{\max }(\mathrm{h})$, the peak time; $V_{\mathrm{d}}\left(\mathrm{L} / \mathrm{m}^{2}\right)$, Volume of distribution; SD, standard deviation; SEM, standard error.

from conventional doxorubicin injection ${ }^{[12]}$ (Table 5), where the $t_{1 / 2}$ of pegylated liposomal doxorubicin was $68 \mathrm{~h}$, which was 6.58 times longer than conventional doxorubicin injection. Moreover, the area under curve (AUC) of pegylated liposomal doxorubicin increased 260 fold when compared to conventional doxorubicin injection, and the clearance of pegylated liposomal doxorubicin was $0.29 \%$ of conventional doxorubicin injection. This result indicates that pegylated liposomal doxorubicin has a longer retention time in plasma circulation than conventional doxorubicin injection, and the lower $V_{\mathrm{d}}(1.63 \%)$ indicates that it is localized and less distributed in other organs. These results are in agreement with the phase I/II clinical trials conducted by Hong ${ }^{[13,14]}$. Gender did not affect the pharmacokinetic parameters of pegylated liposomal doxorubicin, and no significant difference was found in $\mathrm{AUC}_{0-168 \text {, }}$ $\mathrm{AUC}_{0-\infty}, \mathrm{CL}, C_{\max }, t_{1 / 2}, t_{\max }$ or $V_{\mathrm{d}}(P=0.199-0.684)$ (Table 6).

Table 6. Comparison of pharmacokinetics between male and female patients administered pegylated liposomal doxorubicin.

\begin{tabular}{|c|c|c|c|}
\hline Parameters & Male $(n=6)$ & Female $(n=3)$ & $P$ Value \\
\hline $\operatorname{AUC}_{(0-\infty)}(g / L \cdot h)$ & $0.8 \pm 0.5$ & $1.1 \pm 0.3$ & 0.316 \\
\hline $\mathrm{AUC}_{(0-\mathrm{t})}(\mathrm{g} / \mathrm{L} \cdot \mathrm{h})$ & $0.6 \pm 0.3$ & $0.9 \pm 0.2$ & 0.234 \\
\hline $\mathrm{CL}\left(\mathrm{L} \cdot \mathrm{h}^{-1} \cdot \mathrm{m}^{-2}\right)$ & $0.051 \pm 0.027$ & $0.027 \pm 0.008$ & 0.199 \\
\hline$C_{\max }(\mathrm{mg} / \mathrm{L})$ & $9.5 \pm 2.9$ & $10.8 \pm 3.6$ & 0.605 \\
\hline$t_{1 / 2}(\mathrm{~h})$ & $61 \pm 31$ & $83 \pm 16$ & 0.298 \\
\hline$t_{\max }(\mathrm{h})$ & $4 \pm 4$ & $12 . \pm 11$ & 0.331 \\
\hline$V_{d}\left(L / m^{2}\right)$ & $3.7 \pm 1.2$ & $3.3 \pm 1.1$ & 0.684 \\
\hline
\end{tabular}

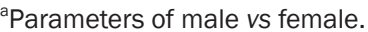

\section{Discussion}

The $\mathrm{CHOP}$ regimen (cyclophosphamide, doxorubicin, vincristine, and prednisolone) has been used extensively to treat patients with PTCL. However, it has resulted in poor outcomes except for cases of anaplasic large-cell-lymphoma kinase (ALK)-positive lymphoma. Moreover, doxorubicin has a low therapeutic index and can induce several adverse effects, such as myelosuppression, as well as heart and digestive system toxicities, especially heart damage caused by drug accumulation $^{[15,16]}$. To avoid doxorubicin toxicities, PLD was used in the current study and evaluated for clinical administration.

PLD is a long-circulating pegylated liposome, which is prone to target cancer cells. Therefore, it can reduce the toxicities associated with doxorubicin, especially the myelosuppression and cardiotoxicity. Owing to its stable spatial structure and encapsulated form, PLD has longer plasma circulation, lower clearance rate, higher blood concentration, and longer $t_{1 / 2}(68 \mathrm{~h})$ when compared with conventional doxorubicin injection. Generally, normal tissues have an integrated capillary wall and most liposomes cannot pass through it, but the permeability of new vessels in tumor tissues is much higher.

Table 5. Comparison of pharmacokinetics between patients administered pegylated liposomal doxorubicin and conventional doxorubicin injection.

\begin{tabular}{|c|c|c|c|c|c|c|c|c|c|c|}
\hline \multirow{3}{*}{ Drug form } & \multirow{3}{*}{ Tumor type } & \multirow{3}{*}{$\begin{array}{c}\text { Dose } \\
\left(\mathrm{mg} / \mathrm{m}^{2}\right)\end{array}$} & \multirow{3}{*}{$n$} & \multicolumn{7}{|c|}{ Parameters } \\
\hline & & & & $C_{\max }$ & $\mathrm{AUC}_{(0-\infty)}$ & & & & $V_{d}$ & $t_{1 / 2}$ \\
\hline & & & & $(\mathrm{mg} / \mathrm{L})$ & (mg/L.h) & $\left(L \cdot h^{-1} \cdot m^{-2}\right)$ & $(\mathrm{L} / \mathrm{h})^{\mathrm{a}}$ & $\left(\mathrm{L} / \mathrm{m}^{2}\right)$ & $(\mathrm{L})^{\mathrm{b}}$ & (h) \\
\hline \multirow[t]{2}{*}{ Conventional doxorubicin $(\mathrm{CD})^{[7]}$} & Misc solid & 50 & 4 & 5.90 & 3.50 & - & 25.30 & - & 365.00 & 10.40 \\
\hline & Rate (PLD/CD) & & & 1.68 & 260 & - & 0.0029 & - & 0.0163 & 0.0029 \\
\hline
\end{tabular}

${ }^{a} \mathrm{CL}(\mathrm{L} / \mathrm{h})=\mathrm{CL}\left(\mathrm{L} \cdot \mathrm{h}^{-1} \cdot \mathrm{m}^{-2}\right) \times$ body surface area $\left(\mathrm{m}^{2}\right) ;{ }^{\mathrm{b}} V_{\mathrm{d}}(\mathrm{L})=\mathrm{CL}\left(\mathrm{L} / \mathrm{m}^{2}\right) \times$ body surface area $\left(\mathrm{m}^{2}\right)$. 
Additionally, liposomal doxorubicin releases more slowly and can directly act on the tumor tissues, which makes doxorubicin better at targeted delivery. Compared to the conventional doxorubicin injection, PLD has improved pharmacodynamics and pharmacokinetics.

Several studies have reported that PLD has good remission and survival rates when used to treat basal T-cell lymphoma of the skin ${ }^{[15,16]}$, which suggests that it is essential to investigate specific treatments for different subtypes of the PTCL. In this study, the ORR of the 11 patients was $45.5 \%$ and the CR rate was $27.3 \%$; the 1-year overall survival rate was $45.5 \%$, and the median PFS and survival time were 6.5 months (95\% CI 3.17-19.02) and 11.5 months (95\% CI 8.07-21.24), respectively. For the seven chemonaive patients, the ORR was $71.4 \%$ and the CR was $42.9 \%$. The results were consistent with results previously described in detail using the CHOP regimen ${ }^{[15-19]}$.

The grade $3 / 4$ toxicities were myelosuppression including anemia (one case, 9.1\%), neutropenia (three cases, $27.3 \%$ ), and thrombocytopenia (one case, 9.1\%), which were higher than other CHOP regimen reports ${ }^{[19,20]}$. However, there was no cardiac toxicity case in this study. Dose-dependent cardiac toxicity is a main side effect of doxorubicin, especially in elderly patients where there is a high rate of pre-existing cardiac disease $^{[21]}$. However, cardiac toxicity is common even in younger patients ${ }^{[22]}$. It has also been reported that PLD has low concentrations in the heart, kidney, stomach, and small intestine, which reduces the incidence of adverse effects in these organs normally induced by free doxorubicin ${ }^{[23]}$. Therefore, the CCOP regimen has a better therapeutic index than the CHOP regimen with equivalent or superior efficacy and lower toxicity. Of the four relapsed patients, three experienced a short paracmasis. Thus, other new regimens are still needed to treat these types of patients. The results of the pharmacokinetic parameters (Table 5) indicate that PLD had a long circulation time in the plasma, enhancing accumulation in tumor tissues, and demonstrating a superior therapeutic activity over free doxorubicin. There were no significant differences in pharmacokinetic parameters of PLD due to the patients' gender (Table 6).

Although the data from this study of the pharmacokinetics and toxicity profile of the CCOP regimen are very favorable and encouraging, further investigations with more patients and randomized controlled studies in comparison to the CHOP regimen are warranted before new PTCL treatment guidelines can be proposed.

\section{Acknowledgements}

This work was sponsored by the Zhejiang Provincial Program for the Cultivation of High-level Innovative Health Talents as well as the Medical Science Research Foundation of Zhejiang Province, China (№ 2006B010). We would like to thank Ben Venue Laboratories Inc and Zhejiang Hisun Pharmaceutical Co Ltd for providing pegylated liposomal doxorubicin and the standard references of doxorubicin and daunorubicin.

\section{Author contribution}

Yun FAN and Neng-ming LIN designed the research; Yun FAN, Lü-hong LUO, Luo FANG, Zhi-yu HUANG, Hai-feng YU, and Feng-qin WU performed the research; and Yun FAN and Neng-ming LIN analyzed the data and wrote the paper.

\section{References}

1 Savage KJ, Chhanabhai M, Gascoyne RD, Connors JM. Characterization of peripheral T-cell lymphomas in a single North American institution by the WHO classification. Ann Oncol 2004; 15: 1467-75.

2 Vose J, Armitage J, Weisenburger D; International T-Cell Lymphoma Project. International peripheral T-cell and natural killer/T-cell lymphoma study: pathology findings and clinical outcomes. J Clin Oncol 2008; 26: 4124-30.

3 Nickelsen M, Ziepert M, Zeynalova S, Glass B, Metzner B, Leithaeuser $\mathrm{M}$, et al. High-dose CHOP plus etoposide (MegaCHOEP) in T-cell lymphoma: a comparative analysis of patients treated within trials of the German High-Grade Non-Hodgkin Lymphoma Study Group (DSHNHL). Ann Oncol 2009; 20: 1977-84.

4 Reimer P, Rüdiger T, Geissinger E, Weissinger F, Nerl C, Schmitz N, et al. Autologous stem-cell transplantation as first-line therapy in peripheral T-cell lymphomas: results of a prospective multicenter study.J Clin Oncol 2009; 27: 106-13.

5 Morabito F, Gallamini A, Stelitano C, Callea V, Guglielmi C, Neri S, et al. Clinical relevance of immunophenotype in a retrospective comparative study of 297 peripheral T-cell lymphomas unspecified, and 496 diffuse large B-cell lymphomas: experience of the Intergruppo Italiano Linfomi. Cancer 2004; 101: 1601-8.

6 Rüdiger T, Weisenburger DD, Anderson JR, Armitage JO, Diebold J, MacLennan KA, et al. Peripheral T-cell lymphoma (excluding anaplastic large-cell lymphoma): results from the Non-Hodgkin's Lymphoma Classification Project. Ann Oncol 2002; 13: 140-9.

7 Gabizon A, Catane R, Uziely B, Kaufman B, Safra T, Cohen R, et al. Prolinged circulation time and enhanced accumulation in malignant exudates of doxorubicin encapsulated in polyethylene-glycol coated liposomes. Cancer Res 1994; 54: 987-92.

8 Gabizon A, Shmeeda H, Barenholz SR. Pharmacokinetics of pegylated liposomal doxorubicin: review of animal and human studies. Clin Pharmacokinet 2003; 42: 419-36.

9 Quereux G, Marques S, Nguyen JM, Bedane C, D'incan M, Dereure 0 , et al. Prospective multicenter study of pegylated liposomal doxorubicin treatment in patients with advanced or refractory mycosis fungoides or Sézary syndrome. Arch Dermatol 2008; 144: 727-33.

10 Pulini S, Rupoli S, Goteri G, Pimpinelli N, Alterini R, Tassetti A, et al. Pegylated liposomal doxorubicin in the treatment of primary cutaneous T-cell lymphomas. Haematologica 2007; 92: 686-9.

11 Visani G, Guiducci B, D’Adamo F, Mele A, Nicolini G, Leopardi G, et al. Cyclophosphamide, pegylated liposomal doxorubicin, vincristine and prednisone (CDOP) plus rituximab is effective and well tolerated in poor performance status elderly patients with non-Hodgkin's lymphoma. Leuk Lymphoma 2005; 46: 477-9.

12 Crawford J. Clinical uses of pegylated pharmaceuticals in oncology. Cancer Treat Rev 2002; 28: 7-11.

13 Hong RL, Tseng YL. Phase I and pharmacokinetic study of a stable, polyethylene-glycolated liposomal doxorubicin in patients with solid tumors. Cancer 2001; 91: 1826-33.

14 Hong RL, Tseng YL. A phase II and pharmacokinetic study of pegylated liposomal doxorubicin in patients with advanced hepatocellular carcinoma. Cancer Chemother Pharmacol 2003; 51: 433-8. 
15 Pan ZH, Huang HQ, Cai QQ, Bo Q, Wang BF, Liao H. Clinical analysis of prognosis for 96 patients with peripheral T-cell lymphoma. Chin J Clin Oncol 2007; 34: 702-5.

16 Savage KJ. Prognosis and primary therapy in peripheral T-cell lymphomas. Hematology Am Soc Hematol Educ Program 2008: 2808.

17 Giri SN, Al-Bayati MA, Du X, Schelegle E, Mohr FC, Margolin SB. Amelioration of doxorubicin-induced cardiac and renal toxicity by pirfenidone in rats. Cancer Chemother Pharmacol 2004; 53: 141-50.

18 Schmitz N, Trümper L, Ziepert M, Nickelsen M, Ho AD, Metzner B, et al. Treatment and prognosis of mature T-cell and NK-cell lymphoma: an analysis of patients with T-cell lymphoma treated in studies of the German High-Grade Non-Hodgkin's Lymphoma Study Group (DSHNHL). Blood 2010; 116; 3418-25.

19 Gallamini A, Zaja F, Patti C, Billio A, Specchia MR, Tucci A, et al. Alemtuzumab (Campath-1H) and CHOP chemotherapy as first-line treatment of peripheral T-cell lymphoma: results of a GITIL (Gruppo
Italiano Terapie Innovative nei Linfomi) prospective multicenter trial. Blood 2007; 110: 2316-23.

20 Vose J, Armitage J, Weisenburger D. International peripheral T-cell and natural killer/T-cell lymphoma study: pathology findings and clinical outcomes. J Clin Oncol 2008; 26: 4124-30.

21 Havlik RJ, Yancik R, Long S, Ries L, Edwards B. The National Institute on Aging and the National Cancer Institute SEER collaborative study on co-morbidity and early diagnosis of cancer in the elderly. Cancer 1994; 74: 2101-6.

22 van der Pal HJ, van Dalen EC, Hauptmann M, Kok WE, Caron HN, van den Bos $\mathrm{C}$, et al. Cardiac function in 5-year survivors of childhood cancer: a long-term follow-up study. Arch Intern Med 2010; 170: 1247-55.

23 Lu WL, Qi XR, Zhang Q, Li RY, Wang GL, Zhang RJ, et al. A pegylated liposomal platform: pharmacokinetics, pharmacodynamics, and toxicity in mice using doxorubicin as a model drug. J Pharmacol Sci 2004; 95: 381-9. 